\title{
Risk factors for early rebleeding after endoscopic band ligation for colonic diverticular hemorrhage
}

Authors

Institution
Takashi Ikeya', Naoki Ishii, Kaoru Nakano, Fumio Omata, Yuto Shimamura, Mai Ego, Koichi Takagi, Kenji Nakamura', Katsuyuki Fukuda' ${ }^{1}$, Yoshiyuki Fujita'

Department of Gastroenterology, St. Luke’s International Hospital, Tokyo, Japan submitted

7. January 2015

accepted after revision

13. April 2015

\section{Bibliography}

DOI http://dx.doi.org/

10.1055/s-0034-1392215

Published online: 12.6.2015

Endosc Int Open 2015; 03:

E523-E528

(C) Georg Thieme Verlag KG

Stuttgart - New York

E-ISSN 2196-9736

\section{Corresponding author}

Naoki Ishii, MD

Department of

Gastroenterology

St. Luke's International Hospital

9-1 Akashi-cho

Chuo-ku

104-8560 Tokyo

Japan

Fax: +81-3-3544-0649

naoishi0328@gmail.com
Background and study aims: Endoscopic band ligation (EBL) has been used for hemostasis of colonic diverticular hemorrhage. However, early rebleeding ( $<30$ days after EBL) has been reported in some cases. The aim of this study was to elucidate risk factors for early rebleeding after EBL in treatment of colonic diverticular hemorrhage.

Patients and methods: A total of 101 patients with definite diverticular hemorrhage treated using EBL from June 2009 to October 2014 were included in the retrospective cohort study and divided into rebleeding and non-rebleeding groups, depending on the presence or absence of early rebleeding. Patients' ages, comorbid diseases, stigmata of recent hemorrhage (SRH) [active bleeding $(A B)$, non-bleeding visible vessel (NBVV), or adherent clot (AC)], locations of bleeding diverticula, and eversions of the diverticula

\section{Introduction \\ $\nabla$}

Colonic diverticular hemorrhage is the most common cause of acute lower gastrointestinal bleeding (LGIB), and therapeutic intervention is needed in severe bleeding cases [1-5]. Several types of endoscopic treatments such as coagulation therapy, epinephrine injection, and endoscopic clipping have been performed to achieve hemostasis of colonic diverticular hemorrhage [6-11]. Endoscopic variceal ligation (EVL) is widely used as a treatment for esophageal variceal bleeding. Recently, endoscopic band ligation (EBL), which uses devices and techniques similar to those for EVL, has been used for hemostasis of colonic diverticular hemorrhage and has been reported as a safe and effective endoscopic treatment for that indication [12-18]. However, rebleeding after EBL was reported in some cases, and the risk factors for it remain to be identified $[16,17]$.

The aim of this retrospective study was to elucidate the risk factors for early rebleeding after EBL after EBL were retrospectively evaluated in each group.

Results: Early rebleeding occurred in 15 cases. The median time (range) of early rebleeding occurrence was 5 days (range, $2 \mathrm{~h}$ to 26 days). Early rebleeding could be managed conservatively and/or endoscopically, except in one case in which surgery was done. Multivariate analysis revealed that age under 50 (adjusted OR, 8.7; 95\% CI 1.652.5; $P=0.014$ ) and $\mathrm{AB}$ (adjusted $\mathrm{OR}, 4.21 ; 95 \% \mathrm{Cl}$ $1.15-18.1 ; P=0.03$ ) were shown to be significant risk factors. The right side of the colon carried less risk than did the left side (adjusted OR, 0.21; 95\% CI 0.04-0.84; $P=0.028$ ).

Conclusions: Younger age, AB of SRH, and leftsided lesions were identified as the risk factors for early rebleeding after EBL in the treatment of colonic diverticular hemorrhage.

following treatment of colonic diverticular hemorrhage.

\section{Patients and methods \\ $\nabla$ \\ Study population}

Endoscopy records for patients with acute LGIB treated at St. Luke's International Hospital in Tokyo from June 2009 to October 2014 were retrospectively reviewed.

During that period, 108 patients with definite diverticular hemorrhage with stigmata of recent hemorrhage (SRH) [active bleeding $(A B)$, nonbleeding visible vessel (NBVV), or adherent clot (AC)] [6] were treated. Patients treated with transcatheter arterial embolization (TAE), epinephrine injection, or endoscopic clipping as a first-line therapy were excluded, and a total of 101 patients with definite diverticular hemorrhage successfully treated using EBL were ultimately included in the retrospective cohort study. 

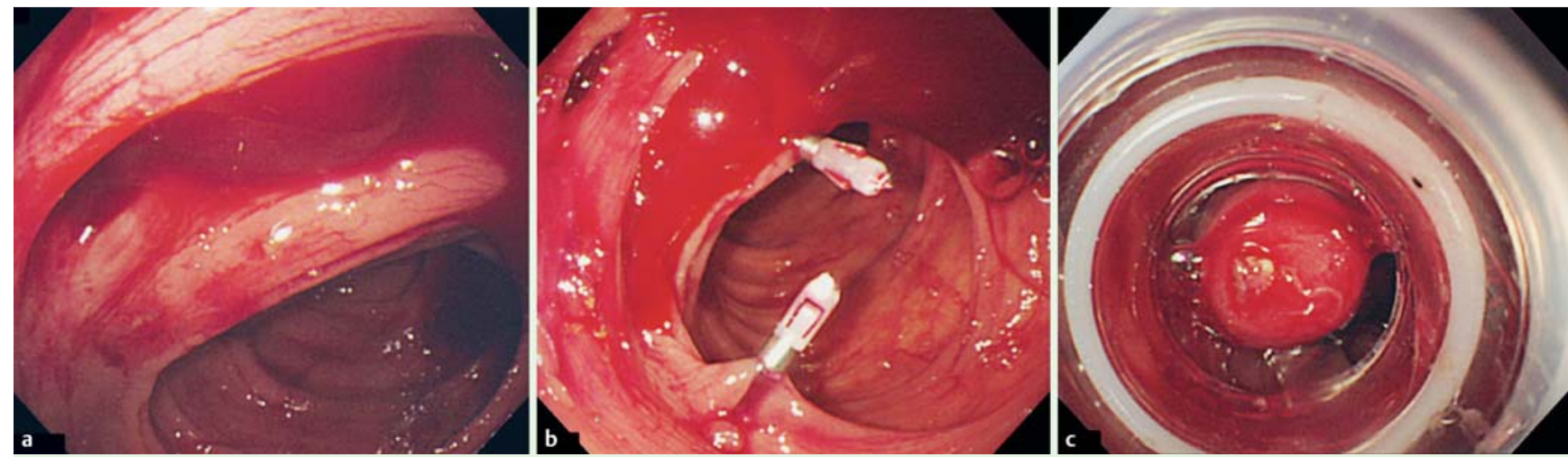

Fig. 1 a Endoscopic view of the colonic diverticulum with active bleeding. b Marking with the hemoclips was done near the diverticulum. c The colonoscope was pulled off and reinserted after attachment of the band ligator. The elastic O-band was released and successful hemostasis was obtained.

EBL methods and repeat colonoscopy for rebleeding The method of EBL for colonic diverticular hemorrhage was the same as that reported in the previous literature [14-17]. Welltrained endoscopists and a trainee supervised by the experts performed EBL in the current study. After fluid resuscitation, bowel purge was done with polyethylene glycol and colonoscopy was performed. When the diverticulum with SRH was detected, the area was marked with ( $\boldsymbol{\bullet}$ Fig. $\mathbf{1} \mathbf{a}$ and $\mathbf{1} \mathbf{b}$ ). Epinephrine injection was not performed for the diverticula with AB before EBL. The colonoscope was removed, the band-ligator device was attached to the tip, and the colonoscope was reinserted. The diverticulum was sucked into the band-ligator and the O-band was released (๑ Fig. 1c).

Patients consumed a liquid meal the day after EBL and were usually discharged a few days after the procedure. Antiplatelet agents or nonsteroidal anti-inflammatory drugs (NSAIDs) were reintroduced the day after EBL, if required. Patients were basically followed on an outpatient basis at St. Luke's International Hospital for at least 30 days after EBL. In patients who had been taking regular meals and experienced rebleeding, a bowel purge with polyethylene glycol was done and repeat colonoscopy was performed using a water-jet scope (PCF-Q260AZI, PCF-Q260JI, or GIF-Q260J; Olympus Medical Systems) to rule out other bleeding sources. In some patients, repeat colonoscopy was performed without a bowel purge. The same gastroenterologists or on-call gastroenterologists performed the repeat colonoscopy. Further treatments were administered based on the judgments of the attending gastroenterologists. Patients who were not followed up at St. Luke's International Hospital were contacted by telephone. This study was approved by the ethics committee of St. Luke's International Hospital, and written informed consent was obtained from all patients.

\section{Comparison between rebleeding and non-rebleeding groups}

The 101 enrolled patients were divided into rebleeding and nonrebleeding groups based on the presence or absence of early rebleeding, which was defined as rebleeding within 30 days after initial treatment [6]. Comorbid diseases (hypertension, hyperlipidemia, and diabetes mellitus), use of antiplatelet agents or NSAIDs, SRH (AB vs. NBVV and AC), location of bleeding diverticula [right colon (cecum, ascending colon, and transverse colon) vs. left colon (descending colon and sigmoid colon)], and the eversion of the diverticula after EBL were retrospectively evaluated in each group.

\section{Statistical analysis}

Statistical analysis was performed using JMP version 9 (SAS Institute Inc., USA). The patients' ages were reported as mean [standard deviation (SD)]. Student's t-test and Fisher's exact test were applied for continuous and categorical variables, respectively, and a $P$ value less than 0.05 was considered statistically significant. Odds ratios (ORs) and their 95\% confidence intervals (CI) were calculated by multiple logistic regression analysis.

\section{Results}

$\nabla$

\section{Characteristics of rebleeding cases after EBL}

The characteristics of 15 early rebleeding patients are listed in - Table 1. Early rebleeding occurred in $15 \%$ of the patients (cecum, $n=4$; ascending colon, $n=3$; transverse colon, $n=1$; descending colon, $\mathrm{n}=1$; sigmoid colon, $\mathrm{n}=6$ ). The median time (range) of early rebleeding occurrence was 5 days (range, $2 \mathrm{~h}$ to 26 days).

In two cases (cases 1 and 2 ) where rebleeding occurred at $2 \mathrm{~h}$ and $11 \mathrm{~h}$ after initial EBL, dislodgement of the O-band was observed in repeat colonoscopy, and EBL was repeated ( $\bullet$ Fig. 2). Complete eversion of the banded diverticula had not been achieved during the first EBL sessions in either case.

Ulceration was observed at the banded site in repeat colonoscopy in four early rebleeding cases. Two of those patients (cases 3 and 4) underwent endoscopic clipping at the visible vessel on the ulcer base ( $\bullet$ Fig. 3). No interventions were required in the other two patients (cases 5 and 6 ), owing to the absence of visible vessels.

The banded diverticula transformed into yellowish or black balls on repeat colonoscopy performed in five early rebleeding cases (cases 7-11) ( $\bullet$ Fig. 4), which had no other demonstrable bleeding sources. Eversion of the diverticula after EBL had been observed during the first EBL in five cases. In one of these five cases (case 7), right hemicolectomy was performed as the patient's preference, whereas the other four cases were managed conservatively without any interventions.

In twoearly rebleeding cases (cases 13 and 14), repeat colonoscopy $11 \mathrm{~h}$ and 24 days after the initial EBL demonstrated active bleeding from the diverticula that differed from the bleeding seen previously, and EBL was repeated. Hemostasis was obtained, and rebleeding did not occur during the follow-up periods of 59 and 37 months, respectively. In case 15, repeat colonoscopy showed scar formation at the previously banded site. However, 
Table 1 Characteristics of 15 early rebleeding cases after EBL.

\begin{tabular}{|c|c|c|c|c|c|c|c|c|}
\hline No. & Age & Gender & Location & $\begin{array}{l}\text { Eversion } \\
\text { after } \\
\text { initial EBL }\end{array}$ & $\begin{array}{l}\text { Time to } \\
\text { rebleeding } \\
\text { after EBL } \\
\text { (hours or days) }\end{array}$ & $\begin{array}{l}\text { Time to } \\
\text { repeat endoscopy } \\
\text { (hours or days) }\end{array}$ & $\begin{array}{l}\text { Endoscopic feature } \\
\text { at the initial EBL sites }\end{array}$ & $\begin{array}{l}\text { Additional } \\
\text { treatments }\end{array}$ \\
\hline 1 & 69 & M & $S$ & $(-)$ & 2 & 20 & Dislodgement of O-ring & Repeat EBL \\
\hline 2 & 75 & M & $S$ & $(-)$ & 11 & 17 & Dislodgement of O-ring & Repeat EBL \\
\hline 3 & 46 & M & A & $(+)$ & 10 & 56 & Ulcer with visible vessel & Clip \\
\hline 4 & 34 & M & C & $(+)$ & 44 & 53 & Ulcer with visible vessel & Clip \\
\hline 5 & 67 & M & C & $(-)$ & 66 & 75 & Ulcer without visible vessel & $\begin{array}{l}\text { Conservative } \\
\text { management }\end{array}$ \\
\hline 6 & 93 & M & S & $(+)$ & 12 days & 12 days & Ulcer without visible vessel & $\begin{array}{l}\text { Conservative } \\
\text { management }\end{array}$ \\
\hline 7 & 37 & M & A & $(+)$ & 13 & 17 & Yellowish tissue & Surgery \\
\hline 8 & 70 & M & A & $(+)$ & 22 & 24 & Yellowish tissue & $\begin{array}{l}\text { Conservative } \\
\text { management }\end{array}$ \\
\hline 9 & 77 & M & $\mathrm{T}$ & $(+)$ & 32 & 35 & Black tissue & $\begin{array}{l}\text { Conservative } \\
\text { management }\end{array}$ \\
\hline 10 & 46 & M & C & $(+)$ & 33 & 49 & Yellowish tissue & $\begin{array}{l}\text { Conservative } \\
\text { management }\end{array}$ \\
\hline 11 & 66 & $\mathrm{~F}$ & $S$ & $(+)$ & 90 & 99 & Yellowish tissue & $\begin{array}{l}\text { Conservative } \\
\text { management }\end{array}$ \\
\hline 12 & 55 & M & $C / A^{1}$ & $(+)$ & 11 & 20 & $\begin{array}{l}\text { Black tissue } \\
\text { (Bleeding from other diverti- } \\
\text { culum) }\end{array}$ & $\mathrm{EBL}$ \\
\hline 13 & 78 & $\mathrm{~F}$ & $\mathrm{D} / \mathrm{S}^{2}$ & $(+)$ & 21 days & 24 days & $\begin{array}{l}\text { Ulcer with no vessel } \\
\text { (Bleeding from other diverti- } \\
\text { culum) }\end{array}$ & EBL \\
\hline 14 & 55 & M & $S$ & $(+)$ & 26 days & 27 days & $\begin{array}{l}\text { Scar formation } \\
\text { (Bleeding from other diverti- } \\
\text { culum) }\end{array}$ & $\begin{array}{l}\text { Conservative } \\
\text { management }\end{array}$ \\
\hline 15 & 94 & $\mathrm{~F}$ & $S$ & $(+)$ & 60 & $(-)$ & No repeat endoscopy & $\begin{array}{l}\text { Conservative } \\
\text { management }\end{array}$ \\
\hline
\end{tabular}

C, cecum; A, ascending colon; T, transverse colon; D, Descending colon; S, sigmoid colon

${ }^{1}$ Initial bleeding sites and early rebleeding site were cecum and ascending, respectively.

2 Initial bleeding sites and early rebleeding site were descending and sigmoid, respectively.
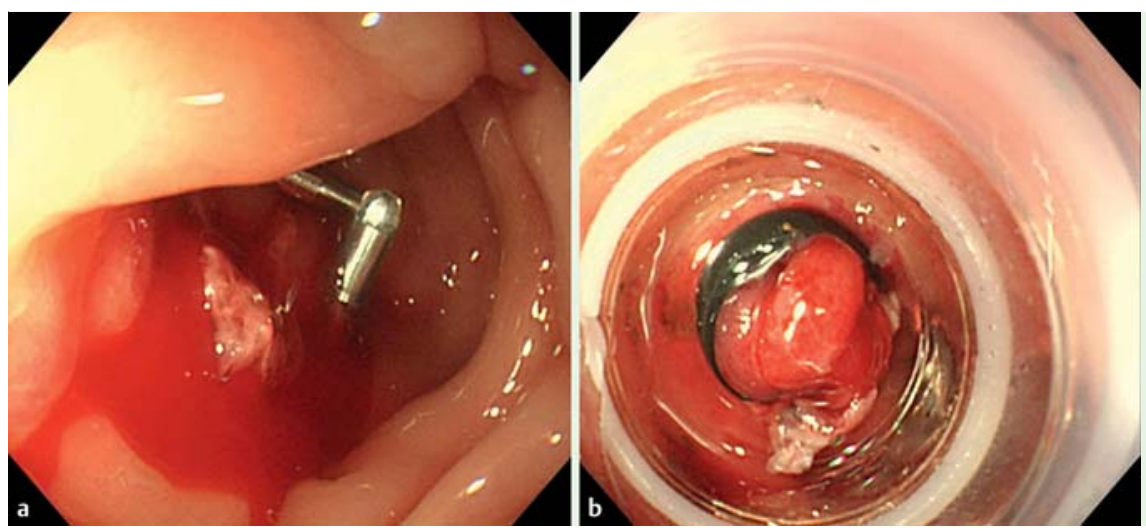

Fig. 2 a Early rebleeding was observed from the previously banded diverticulum, owing to early dislodgement of the O-band (case 1). b Repeat EBL was performed and bleeding stopped.

the rebleeding source was not identified. In case 16 , repeat colonoscopy was not performed, owing to severe cardiopulmonary diseases, and rebleeding was managed conservatively.

\section{Comparison between rebleeding and non-rebleeding groups}

A comparison between 15 rebleeding and 86 non-rebleeding cases is presented in Table 2. No significant differences were noted for the parameters. However, left-sided location and $A B$ of $\mathrm{SRH}$ were more common in the rebleeding group than in the non-rebleeding group, and these differences were considered marginally significant ( $P=0.05$ and $P=0.08$, respectively).
- Table 3 presents results of multivariate analysis of the risk factors of early rebleeding after EBL. This analysis revealed that age younger than 50 (adjusted OR, 8.7; 95\% CI 1.6-52.5; $P=0.014$ ) and $\mathrm{AB}$ (adjusted $\mathrm{OR}, 4.21 ; 95 \% \mathrm{CI} 1.15-18.1 ; P=0.03$ ) were significant risk factors. The right side of the colon carried lesser risk than did the left side (adjusted OR, 0.21; 95\% CI0.04-0.84; $P=$ 0.028). 

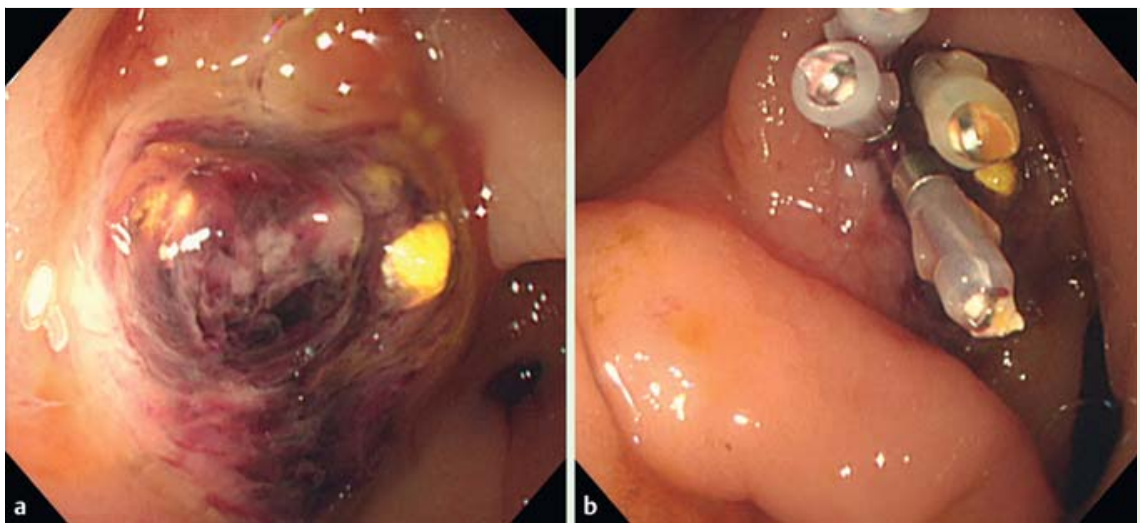

Fig. 3 a A non-bleeding visible vessel was observed at the post-EBL ulcer (case 4). b Endoscopic clipping was performed.

\section{Discussion}

$\nabla$

The aim of this retrospective cohort study of EBL for colonic diverticular hemorrhage was to determine the risk factors for rebleeding after EBL. In the current study, repeat colonoscopy was performed for early rebleeding after EBL, and further treatments for early rebleeding were selected according to the endoscopic features of post-EBL sites as follows: repeat EBL for early dislodgement of the O-band, endoscopic clipping for visible vessels at the post-EBL ulcer, no intervention in ulcer cases with no visible vessels or in the cases of yellow or black tissues, and EBL for different bleeding diverticula. Importantly, the yellowish or black tissues are considered necrotic tissues after EBL and should not be removed because the muscularis propria may be banded by the $\mathrm{O}$-band and the yellowish or black tissues can contain muscularis propria [17]. Given the results, which indicate that early rebleeding can be managed conservatively and/or by endoscopic treatment (except in one ascending case), repeat colonoscopy can be considered useful for determining information about the banded sites after EBL and for selecting further endoscopic procedures that would obviate the need for more invasive treatments such as surgery.

On repeat colonoscopy, another lesion was identified as the source of bleeding in cases 13 and 14, which might lead to the conclusion that EBL was performed mistakenly on the first lesions targeted. That was not the case, however, because SRH were evident in the diverticula initially treated with EBL. In addition, in this study, early rebleeding was defined as rebleeding within 30 days after initial EBL. Therefore, cases 13 and 14 were not excluded from the analysis.

The vascular anatomy at the diverticulum consists of arcades of arteries from the neck that join and form the artery in the base

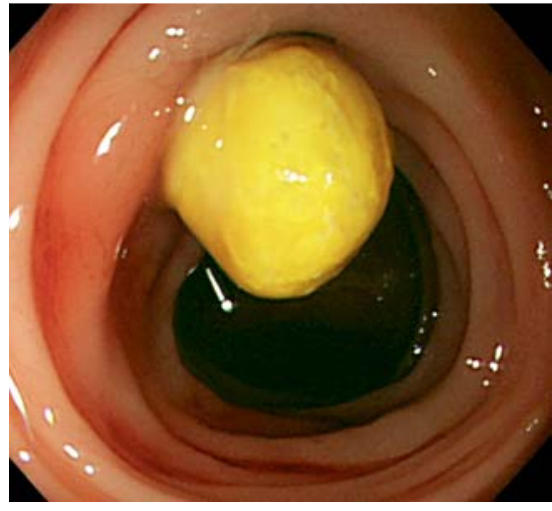

Fig. 4 The banded diverticulum became yellowish on repeat colonoscopy (case 11)

of the diverticulum, and bleeding from the ruptured vasa recta occurs in colonic diverticular hemorrhage [19]. Although the diameter of the vessel at the diverticula and the extent of significant hemorrhage could not be assessed in this study, these factors may contribute to early rebleeding after EBL, given that $A B$ was a significant risk factor for early rebleeding.

Colonic diverticulosis and diverticular bleeding are more common in the right colon of patients from eastern countries including Japan, and a location in the right colon -, especially the ascending colon - was reported as a predictor of refractory colonic diverticular hemorrhage after endoscopic clipping [11]. However, left-sided location was a significant risk factor for early rebleeding after EBL in this study. Ex-vivo study of EBL of the colon using a fresh surgical specimen revealed inclusion by the band ligator of the muscularis propria in the right colon and the submucosa in the left colon [20]., The surgical specimen from the banded diverticulum in the ascending colon also contained the muscularis propria [17]. Given these results, inclusion of the muscularis pro-

\begin{tabular}{|llll|}
\hline & Rebleeding group $(\mathbf{n = 1 5 )}$ & Non-rebleeding group $(\mathbf{n = 8 6})$ & P value \\
\hline Male gender, $\mathrm{n}(\%)$ & $11(73)$ & $63(73)$ & 1.00 \\
\hline Age, mean $\pm \mathrm{SD}($ years) & $63 \pm 17$ & $65 \pm 13$ & 0.46 \\
\hline History of HT, $\mathrm{n}(\%)$ & $8(53)$ & $46(53)$ & 1.00 \\
\hline History of DM, $\mathrm{n}(\%)$ & $11(13)$ & 1.00 \\
\hline History of HL, $\mathrm{n}(\%)$ & $18(20)$ & 0.18 \\
\hline Antiplatelet agents or NSAIDs, $\mathrm{n}(\%)$ & $5(33)$ & $34(39)$ & 0.77 \\
\hline Location in colon (C/A/T/D/S) & $4 / 3 / 1 / 1 / 6$ & $3 / 57 / 8 / 7 / 11$ & 0.05 \\
\hline Right side (C/A/T), $\mathrm{n}(\%)$ & $8(53 \%)$ & $68(79 \%)$ & 0.08 \\
\hline SRH:AB, $\mathrm{n}(\%)$ & $9(60)$ & $29(33)$ & 0.22 \\
\hline Complete eversion, $\mathrm{n}(\%)$ & $11(73)$ & $76(88)$ & \\
\hline
\end{tabular}

Table 2 Characteristics of rebleeding and non-rebleeding groups.

HT, hypertension; DM, diabetes mellitus; HL, hyperlipidemia; NSAIDs, nonsteroidal anti-inflammatory drugs; C, cecum; A, ascending colon; $\mathrm{T}$, transverse colon; $\mathrm{D}$, descending colon; $\mathrm{S}$, sigmoid colon; SRH, stigmata of recent hemorrhage; $\mathrm{AB}$, active bleeding. Statistical significance was defined as $P<0.05$. 


\begin{tabular}{|c|c|c|c|c|}
\hline & $\begin{array}{l}\text { Crude OR } \\
(95 \% \mathrm{Cl})\end{array}$ & $P$ value & Adjusted OR (95\%Cl) & $P$ value \\
\hline Age under 50 & $\begin{array}{l}3.11 \\
(0.74-11.5)\end{array}$ & 0.11 & $\begin{array}{l}8.7 \\
(1.6-52.5)\end{array}$ & 0.014 \\
\hline Male gender & $\begin{array}{l}1.00 \\
(0.3-3.9)\end{array}$ & 1.00 & & \\
\hline History of HT & $\begin{array}{l}0.99 \\
(0.33-3.01)\end{array}$ & 1.00 & & \\
\hline History of DM & $\begin{array}{l}1.05 \\
(0.15-4.52)\end{array}$ & 0.95 & & \\
\hline History of HL & $\begin{array}{l}2.51 \\
(0.76-7.95)\end{array}$ & 0.13 & $\begin{array}{l}2.97 \\
(0.78-11.4)\end{array}$ & 0.11 \\
\hline Antiplatelet agents or NSAIDs & $\begin{array}{l}0.76 \\
(0.22-2.35)\end{array}$ & 0.67 & & \\
\hline $\begin{array}{l}\text { Right side } \\
\text { (C/A/T) }\end{array}$ & $\begin{array}{l}0.30 \\
(0.1-0.97)\end{array}$ & 0.04 & $\begin{array}{l}0.21 \\
(0.04-0.84)\end{array}$ & 0.028 \\
\hline SRH:AB & $\begin{array}{l}2.94 \\
(1.38-18.7)\end{array}$ & 0.05 & $\begin{array}{l}4.21 \\
(1.15-18.1)\end{array}$ & 0.03 \\
\hline Complete eversion & $\begin{array}{l}0.36 \\
(0.10-1.49)\end{array}$ & 0.15 & $\begin{array}{l}0.34 \\
(0.07-1.74)\end{array}$ & 0.19 \\
\hline
\end{tabular}

Table 3 Multivariate analysis of risk factors of early rebleeding after EBL.

HT, hypertension; DM, diabetes mellitus; HL, hyperlipidemia; NSAIDs, nonsteroidal anti-inflammatory drugs; C, cecum; A, ascending colon; $\mathrm{T}$, transverse colon; $\mathrm{D}$, descending colon; S, sigmoid colon; SRH, stigmata of recent hemorrhage; $\mathrm{AB}$, active bleeding; Statistical significance was defined as $P<0.05$; OR, odds ratio; $\mathrm{Cl}$, confidence intervals.

pria in the O-band may be necessary to prevent early rebleeding when using EBL to treat colonic diverticular hemorrhage. Therefore, a diverticular location in the left colon should be considered as a risk factor specific to EBL rather than an overall risk factor for diverticular rebleeding.

Non-eversion of the diverticula after EBL, on the other hand, was not a risk factor for early rebleeding after EBL. As a consequence, EBL may be useful for treatment of stigmata regardless of eversion of the banded diverticular, if reliable banding is obtained and EBL can occlude either the major SRH or the underlying artery.

Hypertension, arteriosclerosis, and regular use of anti-platelet agents or NSAIDs have been reported to be risk factors for colonic diverticular hemorrhage [21-24]. In general, younger patients are considered to have fewer comorbidities, but in this study, younger age was a risk factor for early rebleeding after EBL. The reason for this association could not be identified, and further studies are necessary to clarify the relationship of age to risk of rebleeding after EBL.

The rebleeding from the diverticula seen in this study differed from outcomes with previously banded diverticula in three rebleeding cases, and in some rebleeding cases, bleeding sources other than the banded site were not identified with certainty in repeat colonoscopy. Specifically, the three cases reported here may not be "early rebleeding cases," as the latter cases were. However, the sources of early rebleeding after endoscopic treatments were considered to be from the same diverticula treated endoscopically, although that was not fully established.

Establishing risk factors for recurrent bleeding after EBL may not change the treatment strategy and another endoscopic treatment or surgery may be desirable in patients who have risk factors. With the exception of one case in which surgery was performed because of patient preference, neither surgery nor TAE was not needed to control early rebleeding because management was possible with conservative therapy and/or endoscopic clipping in this study. Previously banded diverticula also may resolve after EBL, preventing late rebleeding from the same diverticula [17]. Therefore, if there are no particular concerns, EBL is considered the first priority. It may be useful to identify risk factors for early rebleeding after EBL so that patients with colonic diverticular hemorrhage who those risk factors can be closely followed.

In conclusion, although the number of patients was limited and the study design was retrospective, younger age, AB of SRH, and left-sided lesions were identified as the risk factors of early rebleeding after EBL in the treatment of colonic diverticular hemorrhage.

\section{Competing interests: None}

\section{References}

1 Longstreth GF. Epidemiology and outcome of patients hospitalized with acute lower gastrointestinal hemorrhage: a population-based study. Am J Gastroenterol 1997; 92: 419-424

2 Chaudhry V, Hyser MJ, Gracias VH et al. Colonoscopy: the initial test for acute lower gastrointestinal bleeding. Am Surg 1998; 64: 723 - 728

3 Newman J, Fitzgerald JE, Gupta S et al. Outcome predictors in acute surgical admissions for lower gastrointestinal bleeding. Colorectal Dis 2012; 14: 1020 - 1026

4 McGuire HHJr. Bleeding colonic diverticula. A reappraisal of natural history and management. Ann Surg 1994; 220: 653-656

5 Poncet G, Heluwaert F, Voirin D et al. Natural history of acute colonic diverticular bleeding: a prospective study in 133 consecutive patients. Aliment Pharmacol Ther 2010; 32: 466 - 471

6 Jensen DM, Machicado GA, Jutabha R et al. Urgent colonoscopy for the diagnosis and treatment of severe diverticular hemorrhage. $\mathrm{N}$ Engl J Med 2000; 342: 78-82

7 Bloomfeld RS, Rockey DC, Shetzline MA. Endoscopic therapy of acute diverticular hemorrhage. Am J Gastroenterol 2001; 96: 2367-2372

8 Hokama A, Uehara T, Nakayoshi T et al. Utility of endoscopic hemoclipping for colonic diverticular bleeding. Am J Gastroenterol 1997; 92: $543-546$

9 Yen EF, Ladabaum U, Muthusamy VR et al. Colonoscopic treatment of acute diverticular hemorrhage using endoclips. Dig Dis Sci 2008; 53: $2480-2485$

10 Kaltenbach $T$, Watson $R$, Shah J et al. Colonoscopy with clipping is useful in the diagnosis and treatment of diverticular bleeding. Clin Gastroenterol Hepatol 2012; 10: 131-137

11 Ishii $N$, Hirata $N$, Omata $F$ et al. Location in the ascending colon is a predictor of refractory colonic diverticular hemorrhage after endoscopic clipping. Gastrointest Endosc 2012; 76: 1175-1181

12 Witte JT. Band ligation for colonic bleeding: modification of multiband ligating devices for use with a colonoscope. Gastrointest Endosc 2000; 52: $762-765$ 
13 Farrell JJ, Graeme-Cook F, Kelsey PB. Treatment of bleeding colonic diverticula by endoscopic band ligation: an in-vivo and ex-vivo pilot study. Endoscopy 2003; 35: 823-829

14 Ishii $N$, Itoh T, Uemura $M$ et al. Endoscopic band ligation with a waterjet scope for the treatment of colonic diverticular hemorrhage. Dig Endosc 2010; 22: 232-235

15 Ishii $N$, Uemura $M$, Itoh $T$ et al. Endoscopic band ligation for the treatment of bleeding colonic and ileal diverticula. Endoscopy 2010; 42: $82-83$

16 Setoyama T, Ishii N, Fujita Y. Endoscopic band ligation (EBL) is superior to endoscopic clipping for the treatment of colonic diverticular hemorrhage. Surg Endosc 2011; 25: 3574-3578

17 Ishii N, Setoyama T, Deshpande GA et al. Endoscopic band ligation (EBL) for colonic diverticular hemorrhage. Gastrointest Endosc 2012; 75 : $382-387$

18 Shibata S, Shigeno T, Fujimori K et al. Colonic diverticular hemorrhage: the hood method for detecting responsible diverticula and endoscopic band ligation for hemostasis. Endoscopy 2014; 46: 66-69
19 Meyers MA, Alonso DR, Gray GF et al. Pathogenesis of bleeding colonic diverticulosis. Gastroenterology 1976; 71: 577-583

20 Barker KB, Amold HL, Fillman EP et al. Safety of band ligator use in the small bowel and the colon. Gastrointest Endosc 2005; 62: 224-227

21 Yamada A, Sugimoto T, Kondo $S$ et al. Assessment of the risk factors for colonic diverticular hemorrhage. Dis Colon Rectum 2008; 51: 116 120

22 Strate $L L$, Liu YL, Huang ES et al. Use of aspirin or nonsteroidal anti-inflammatory drugs increases risk for diverticulitis and diverticular bleeding. Gastroenterology 2011; 140: 1427-1433

23 Niikura R, Nagata N, Akiyama J et al. Hypertension and concomitant arteriosclerotic diseases are risk factors for colonic diverticular bleeding: a case-control study. Int J Colorectal Dis 2012; 27: 1137-1143

24 Okamoto T, Watabe H, Yamada $A$ et al. The association between arteriosclerosis related diseases and diverticular bleeding. Int J Colorectal Dis 2012; 27: $1161-1166$ 